\title{
Fluid balance in pediatric patients in prone position: a pragmatic study
}

(iD) Rosirene Maria Frohlich Dall' Agnese $e^{\mathbf{1}, 2}$

(iD) Petrônio Fagundes de Oliveira Filho

(iD Caroline A. D. Costa

(D) Cristian T. Tonia/1

(iD)Francisco Bruno ${ }^{1}$

(iD) Paulo R. Enloft ${ }^{1}$

(iD) Humberto H. Fiori ${ }^{1}$

(iD) Pedro Celiny R-. Garcia ${ }^{1}$

1. Pontifical Catholic University of Rio Grande do Sul (PUCRS)/ Postgraduate Program on Pediatrics and Children's Health/ São Lucas Hospital of PUCRS - Porto Alegre, RS, Brasil 2. University of Caxias do Sul (UCS), Caxias do Sul, RS, Brasil

http://dx.doi.org/10.1590/1806-9282.65.6.839

\section{SUMMARY}

OBJECTIVE: To verify the association between prone position, increased diuresis, and decreased cumulative fluid balance in critically ill pediatric patients who underwent mechanical ventilation (MV) for pulmonary causes and describe adverse events related to the use of the position.

METHODS: This is a retrospective observational study. Patients aged between 1 month and 12 years who underwent MV for pulmonary causes, between January 2013 and December 2015, were selected and divided between those who were put on prone position (PG) and those who were not (CG) during the hospitalization at the Pediatric Intensive Care Unit (PICU). Data were analyzed longitudinally from $D 1$ to D4.

RESULTS: A total of 77 patients $(P G=37$ and $C G=40)$ were analyzed. The general characteristics of both groups were similar. In the comparison between the groups, there was no increase in diuresis or decrease in cumulative fluid balance in the prone group. In the longitudinal analysis of D1 to D4, we saw that the PG presented higher diuresis $(p=0.034)$ and a lower cumulative fluid balance $(p=$ $0.001)$ in D2. Regarding the use of diuretics, there was greater use of furosemide $(P<0.001)$ and spironolactone $(P=0.04)$ in the $P G$. There was no increase in adverse events during the use of the prone position.

CONCLUSION: The prone position was not associated with increased diuresis or decreased cumulative fluid balance in critically ill pediatric patients who underwent to MV for pulmonary causes.

KEYWORDS: Prone position. Diuresis. Water Balance. Positive-Pressure Respiration. Intensive Care Units, Pediatric.

\section{INTRODUCTION}

Respiratory illnesses in pediatrics are often the cause for hospitalization and admission into a Pediatric Intensive Care Unit (PICU). The evolution of these scenarios into respiratory failure requires invasive ventilation $^{1,2}$. Patients on mechanical ventilation are more prone to fluid retention due to both increased antidiuretic hormone (ADH) secretion and activation of the renin-angiotensin-aldosterone system, as well 
as the peripheral vasoplegia induced by the use of sedatives and analgesics, such as benzodiazepines and opioids. Such retention is aggravated by the lack of limb mobilization, which reduces the "pump" effect of the musculature on venous return, and by the aggressive fluid resuscitation that some patients require due to the severity of their condition, leading a positive cumulative fluid balance $(\mathrm{FB})$ and, consequently, to a fluid overload ${ }^{3,4}$.

Previous studies have demonstrated that a positive cumulative fluid balance in adult and pediatric patients on mechanical ventilation is associated with unfavorable outcomes, such as worse oxygenation levels, longer hospital stays, and increased mortality ${ }^{4-6}$. There is an interest in finding alternatives for the optimization of the fluid balance and, consequently, improving results for pediatric patients. There is evidence that the fluid restriction and proper maintenance of the urinary debt can improve pulmonary function and decrease the duration of mechanical ventilation. Among these alternatives are the stimulation of diuresis through the use of diuretics and vasoactive drugs, eventual renal replacement therapy and, less frequently, the use of the prone position $(\mathrm{PP})^{7-9}$. Evidence that the prone position increases the volume of diuresis are scarce, and this has been described as a secondary outcome in a single study ${ }^{8}$.

Therefore, our objective was to investigate the association between the prone position, increased diuresis, and decreased cumulative fluid balance in critically ill pediatric patients undergoing mechanical ventilation for pulmonary causes, in addition to describing possible adverse events related to the implementation of the position.

\section{METHODS}

A retrospective cohort study was conducted by reviewing medical charts from a Pediatric Intensive Care Unit (PICU) of a university hospital at tertiary level. The unit consists of 12 beds with an average of 450 admissions per year. Fifty percent of the patients are submitted to mechanical ventilation (MV), and the overall mortality rate is $6 \%$. Databases are constantly updated, and various institutional protocols apply for clinical conditions.

We selected inpatients aged between 1 month and 12 years submitted to mechanical ventilation for pulmonary causes in the period from January 2013 to December 2015. The criterion for stratification be- tween the prone group (PG) and control group (CG) was the use of the prone position during hospitalization. We excluded patients with chronic lung disease, who underwent tracheotomy, requiring renal replacement therapy, chronically using diuretics, who did not have sufficient data on the medical chart or with less than four days of mechanical ventilation time.

The demographic data, variables in question (age, sex, weight at admission, mortality score according to the Pediatric Index of Mortality 2 [2] PIM) ${ }^{10}$, primary diagnosis (the cause for hospitalization), secondary diagnosis (relevant finding, but not the cause for hospitalization), profile of respiratory viruses, need and time on MV, the relationship between the PP time and MV time, death, hospitalization time in PICU and in the hospital were recorded in individual charts.

The following data were obtained daily from each patient: fluid balance, diuresis, MV parameters, use of diuretics and vasoactive drugs, time of prone position (with prone position time equal to zero for the patients in the control group). We also considered complications that occurred during the period of mechanical ventilation. The fluid balance was calculated from the enteral and parenteral administration volume minus the volume eliminated, including urine, feces, gastric residue, blood loss, and fluids surgically drained in $\mathrm{ml} / \mathrm{kg} / \mathrm{day}$. The diuresis of each patient was registered in $\mathrm{ml} / \mathrm{kg} / \mathrm{h}$ and the total fluid balance, positive or negative, in $\mathrm{ml} / \mathrm{kg} /$ day, all recorded in intervals of 24 hours from the day mechanical ventilation was started until the day of the extubation. The daily dose of diuretics administered was described in $\mathrm{mg} / \mathrm{kg} /$ day. We calculated the index of vasoactive drugs (IVD), at the time of the morning medical visit, using the formula [dopamine + dobutamine + (epinephrine X 100) + (norepinephrine X 100) + (milrinone X 10)], with all drugs expressed in mcg/ $\mathrm{kg} / \min ^{11}$.

In relation to the outcomes, patients were divided into two groups: prone and control. The main outcomes were increased diuresis and reduced cumulative fluid balance. The secondary outcomes were the number of MV days and days in the PICU and in the hospital. The tests used for the analysis of variables were the Mann-Whitney test and the chi-square test or Fisher's exact test. To analyze the relationship between the variables (prone position, increased diuresis, days of MV, sex, age, weight, PIM2, and flu- 
id balance), we used the generalized linear model. We considered as statistically significant a value of $\mathrm{p}<0.15$ in the univariate analysis for inclusion in the multivariate analysis, and a value of $p<0.05$ in the multivariate analysis (ANOVA). For the longitudinal analysis, we decided to conduct an ANOVA for repeated measures in four moments (D1 to D4 in both groups - PG and CG). By means of the ANOVA, we compared the diuresis, fluid balance, and the use of furosemide. All analyses were performed using the SPSS software version 20.0.

For the control group, D1 is equivalent to the first day of MV; D2 to D4 are the following days during which the patient remained on MV (and at no time during that period the ventilation was in prone position). For the prone group, D1 is equivalent to the day (24 hours before) before the prone position was started; D2 to D4 are the days following days, during which the patient may or may not have repeated the prone position. The research was approved by the Research Ethics Committee of the institution.

\section{RESULTS}

Eighty-four patients had their data collected, 77 of which were used for the final analysis. Seven patients were excluded: one for having been submitted to renal replacement therapy, four due to inadequate record of data on the chart, and two due to less than four days of mechanical ventilation time. The sample is characterized in Table 1. Regarding the severity of the patients on the first day of admission, there was no difference in the Pediatric Index of Mortali- ty 2 (PIM 2) scores. In terms of the main diagnosis, bronchiolitis and wheezing in infants were the most common. Four patients had Acute Respiratory Distress Syndrome (ARDS) in the group that received the prone position. There was no difference between the groups in relation to the number of chronic conditions at the time of hospitalization.

In relation to the outcomes, the group that received the prone position presented more time on mechanical ventilation and a longer stay in the PICU. Hospitalization, use of vasoactive drugs, and deaths were similar. The prone group did not, in general, have more serious adverse events compared to the control group. These results are shown in Table 2.

For the patients who were in the prone position, the median of the relationship between the time on prone position and the total time of MV was $16.5 \%$ (IQR 10.7-24.7).The median in hours and the interquartile intervals of PP time for the four days evaluated in the prone group were: D1= zero; D2= 13.0 (8.014.0); D3=12.0 (10.0-16.0); and D4= 0 (0-11.0). Table 3 shows the measures of diuresis, fluid balance, and the dose of furosemide on the four days assessed.

In general, there was no difference between the diuresis $(\mathrm{P}=0.58)$ and fluid balances $(\mathrm{P}=0.15)$ of the two groups. The comparisons stratified per day show that there was a difference in the volume of diuresis $(\mathrm{P}=0.034)$ and in the $\mathrm{FB}(\mathrm{P}=0.001)$ only in $\mathrm{D} 2$. With respect to the use of furosemide, whose average doses were measured at the same moments of the diuresis and FH, there was a difference in the dose of the diuretics between the treatment groups on all days evaluated $(P<0.001)$.

TABLE 1. CHARACTERIZATION OF THE SAMPLE

\begin{tabular}{|c|c|c|c|}
\hline & $\begin{array}{l}\text { Prone Group } \\
n=37\end{array}$ & $\begin{array}{l}\text { Control Group } \\
n=42\end{array}$ & P-value \\
\hline Age (months); median (IQR) & $3.0(2.0-6.0)$ & $4.0(2.0-9.0)$ & 0.485 \\
\hline Male; $n(\%)$ & $22.0(59.5 \%)$ & $23.0(54.8 \%)$ & 0.674 \\
\hline Mortality score PIM2; median (IQR) & $2.0(1.0-5.3)$ & $1.1(0.9-5.3)$ & 0.914 \\
\hline $\begin{array}{l}\text { Main diagnosis; } \mathrm{n}(\%) \\
\text { Bronchiolitis / Wheezing baby } \\
\text { Pneumonia / Pneumonia with pleural effusion } \\
\text { Others }\end{array}$ & $\begin{array}{l}33(89.2 \%) \\
4(10.8 \%) \\
0(0 \%)\end{array}$ & $\begin{array}{l}34(81.0 \%) \\
6(14.2 \%) \\
2(4.8 \%)\end{array}$ & $\begin{array}{l}0.308 \\
0.643 \\
0.178\end{array}$ \\
\hline $\begin{array}{l}\text { MV parameters (first } 3 \text { days of } M V) \\
\text { PIP }(\mathrm{cmH} 2 \mathrm{O}) \text {, mean }(\mathrm{SD}) \\
\text { PEEP }(\mathrm{cmH} 2 \mathrm{O}) \text {, mean }(\mathrm{SD}) \\
\mathrm{FiO} 2(\%)\end{array}$ & $\begin{array}{l}32.9(3.5) \\
5.7(1.7) \\
0.45(0.15)\end{array}$ & $\begin{array}{l}29.6(4.6) \\
5.3(1.5) \\
0.40(0.11)\end{array}$ & $\begin{array}{l}<0.01 \\
0.054 \\
0.01\end{array}$ \\
\hline
\end{tabular}

Legend: $\mathrm{IQR}$ = interquartile range; $\mathrm{SD}=$ standard deviation; $\mathrm{PIM} 2$ = Pediatric Index of Mortality 2; VM = mechanical ventilation; = PIP peak inspiratory pressure; PEEP = positive end-expiratory pressure; $\mathrm{FiO} 2$ = fraction of inspired oxygen.

For antisymmetric variables, we used the Mann-Whitney test; for symmetric variables, the Student's t-test was used; for categorical variables we used the chi-square test or Fisher's exact test. 
TABLE 2. COMPARISON OF OUTCOMES

\begin{tabular}{|c|c|c|c|}
\hline & $\begin{array}{l}\text { Prone Group } \\
\mathrm{n}=37\end{array}$ & $\begin{array}{l}\text { Control Group } \\
n=42\end{array}$ & P-value \\
\hline Time of MV (days); median (IQR) & $9.9(7.1-12.2)$ & $6.7(4.8-8.6)$ & $<0.001$ \\
\hline Length of stay in the PICU (days); median (IQR) & $14.0(10.0-19.0)$ & $10.5(7.0-14.0)$ & $<0.001$ \\
\hline Length of hospital stay (days); median (IQR) & $21.0(16.0-27.0)$ & $18.0(15.0-24.0)$ & 0.460 \\
\hline Death; n (\%) & $1.0(2.7 \%)$ & $1.0(2.4 \%)$ & 0.927 \\
\hline $\begin{array}{l}\text { Diuretics } \\
\text { Furosemide (mg/kg/day); median (IQR) } \\
\text { Spironolactone (mg/kg/day); median (IQR) }\end{array}$ & $\begin{array}{l}1.62(1.29-2.33) \\
0.91(0.56-1.43)\end{array}$ & $\begin{array}{l}1.04(0.58-1.40) \\
0.71(0-1.11)\end{array}$ & $\begin{array}{l}<0.001 \\
0.04\end{array}$ \\
\hline Index of vasoactive drugs; median (IQR) & $9.11(6.54-12.89)$ & $10.0(6.25-14.55)$ & 0.906 \\
\hline $\begin{array}{l}\text { Intercurrent event; } n(\%) \\
\text { Absent } \\
\text { Pneumothorax } \\
\text { CA on prone position } \\
\text { CA on supine position } \\
\text { Accidental extubation during prone position } \\
\text { Accidental extubation during supine position } \\
\text { Extubation failure } \\
\text { Others }\end{array}$ & $\begin{array}{l}27(73.0 \%) \\
2(5.4 \%) \\
1(2.7 \%) \\
2(5.4 \%) \\
0(0 \%) \\
1(2.7 \%) \\
1(2.7 \%) \\
3(8.1 \%)\end{array}$ & $\begin{array}{l}35(83.3 \%) \\
3(7.1 \%) \\
0(0 \%) \\
0(0 \%) \\
0(0 \%) \\
1(2.4 \%) \\
1(2.4 \%) \\
2(4.8 \%)\end{array}$ & $\begin{array}{l}0.263 \\
0.751 \\
--- \\
--- \\
--- \\
0.927 \\
0.927 \\
0.542\end{array}$ \\
\hline
\end{tabular}

Legend: $I Q R=$ interquartile range; ${ }^{* *}$ Numerical variables - Mann-Whitney test; Categorical variables - the chi-squared or Fisher's exact test; $C A=C$ ardiac arrest.

TABLE 3. RESULTS OF REPEATED MEASUREMENTS AT FOUR MOMENTS

\begin{tabular}{|c|c|c|c|c|}
\hline Time & $\begin{array}{l}\text { Prone Group } \\
n=37\end{array}$ & $\begin{array}{l}\text { Control Group* } \\
n=40\end{array}$ & Mean difference $(95 \% \mathrm{Cl})$ & P-value ${ }^{\star *}$ \\
\hline \multicolumn{5}{|c|}{ Diuresis $(\mathrm{ml} / \mathrm{kg} / \mathrm{h})$} \\
\hline Day 1 & $3.19(0.22)$ & $2.90(0.21)$ & $0.29(-0.317$ a 0.895$)$ & 0.345 \\
\hline Day 2 & $3.89(0.20)$ & $3.30(0.19)$ & 0.59 (0.047 a 1.1370) & 0.034 \\
\hline Day 3 & $3.92(0.22)$ & $4.15(0.22)$ & $-0.23(-0.852$ a 0.389$)$ & 0.460 \\
\hline Day 4 & $4.08(0.22)$ & $4.30(0.21)$ & $-0.22(-0.824$ a 0.387$)$ & 0.474 \\
\hline \multicolumn{5}{|c|}{ Fluid balance (ml/kg/day) } \\
\hline Day 1 & $37.57(4.90)$ & $50.11(4.71)$ & $-12.54(-2607$ to 1.00$)$ & 0.069 \\
\hline Day 2 & $13.48(4.40)$ & $34.26(4.23)$ & $-20.77(-32.94$ to -8.61$)$ & 0.001 \\
\hline Day 3 & $15.27(5.17)$ & $7.05(4.97)$ & $8.23(-6.07$ to 22.52$)$ & 0.255 \\
\hline Day 4 & $13.29(4.37)$ & $5.43(4.20)$ & $7.86(-4.22$ to 19.94$)$ & 0.199 \\
\hline \multicolumn{5}{|c|}{ Furosemide (mg/kg/day) } \\
\hline Day 1 & $1.03(0.15)$ & $0.05(0.14)$ & $0.98(0.57$ a 1.38$)$ & $<0.001$ \\
\hline Day 2 & $1.49(0.15)$ & $0.29(0.14)$ & $1.19(0.78$ a 1.61$)$ & $<0.001$ \\
\hline Day 3 & $1.76(0.16)$ & $0.78(0.16)$ & $0.98(0.53$ a 1.43$)$ & $<0.001$ \\
\hline Day 4 & $2.14(0.18)$ & $1.22(0.17)$ & $0.92(0.42$ a 1.42$)$ & $<0.001$ \\
\hline
\end{tabular}

Legend: ${ }^{*}$ Mean (standard error), based on marginal estimates; ${ }^{* \star}$ Adjustment for multiple comparisons.

\section{DISCUSSION}

Our study was one of the few to analyze the prone position in patients with an indication for MV due to pulmonary causes, without necessarily having ARDS as a primary diagnosis. In addition, we focused on the possible "diuretic effect" of this practice. The initial motivation for the study was the clinical observation that patients submitted to the prone position presented an increased diuresis ${ }^{8}$. Since this a safe position, with already some benefits published in the literature, we used the prone position as a routine option for patients with hypoxemia and positive cumulative fluid balance, regardless of their etiological diagnosis ${ }^{8,12-16}$.
The prone position as an alternative for the improvement in oxygenation, lung recruitment, and gas exchange in patients with respiratory failure has been widely studied ${ }^{12,13,17}$. There is also evidence that it could be related to decreased pulmonary lesion caused by MV and increased survival in patients with Acute Respiratory Distress Syndrome ${ }^{14-16}$. However, only one study, whose main objective was to demonstrate the benefit of the position on aspects already known, observed increased diuresis. Pragmatically and globally, we did not identify the same effect of increased diuresis or reduction of the cumulative fluid balance. Because this is a pragmatic study, the patients did not receive the same amount of prone position time nor 
were they put on the prone position at the same stage of disease or severity. Only in D2, in the prone group, there was an increase in diuresis and decrease in the cumulative fluid balance. We believe that such increase in diuresis is related to the stage of the disease and not the "prone effect," since the patients were already in a situation of greater clinical stability, therefore receiving higher doses of diuretics.

When analyzing variables such as time of MV, length of stay in PICU, and use of diuretics, the group that was not put on prone position showed less severe outcomes. We believe this happened because the group had a more favorable clinical evolution, which did encourage the staff to use the prone position during their hospitalization. In clinical practice, patients with more bloating, greater need for oxygen, or with higher cumulative fluid balance tend to be put on the prone position more often. This was shown in the average of MV parameters of the first three days for patients from the prone group.

An important point we evaluated was the equality of adverse events in both positions, as demonstrated by Fineman et al. ${ }^{18}$, which characterize the use of the prone position as a safe practice. Only one patient presented CPR in the prone position. This episode was isolated and does not seem to have a relationship with the position since the patient was in severe clinical condition. There were no accidental extubations in the prone position.

Our study had some limitations. First, the comparison of outcomes in different days of evolution. The initial objective was to verify if the "diuretic effect" of the prone position would appear in usual treatment conditions within a PICU, but that did not occur, even with the use of higher doses of diuretics in this group. To better exemplify this: in the control group, D1 was the first day of mechanical ventilation, in which the patient needed fluid resuscitation to be stabilized. Therefore, until this clinical stability was achieved, these patients did not use diuretics. The prescription of diuretics for patients under MV only happens when their condition evolves; when the objective is precisely to improve the fluid balance, so deleterious to the outcomes of our patients ${ }^{4-6}$. In the prone position, D1 was never the first day of MV, which may have been on D2, D3 or D4. On these days, the patient already has a diuretic prescribed and, often, in increasing doses to minimize the effects of fluid overload. In addition, other factors that were not studied might have interfered with the increased use of diuretics in this group. Another limitation is that most of our patients did not have any ARDS, a disease in which the prone position was more studied with evidence of its benefits. Secondly, the mortality score (PIM2) used in the study predicts the risk of mortality at the time of admission into the PICU, and it is not a dynamic score. It is calculated on the first day of hospitalization. In the prone position, $10.8 \%$ of the patients had a diagnosis of Acute Respiratory Distress Syndrome associated with their primary disease, which in itself increases their severity in relation to the other group. Thus, it is possible that the groups became heterogeneous, despite having similar PIM2 on the first day. This might also justify the longer MV and length of hospitalization in the prone group.

\section{CONCLUSION}

In conclusion, the prone position showed no association with increased diuresis or reduced cumulative fluid balance in critical pediatric patients submitted to MV for pulmonary causes.

\section{RESUMO}

OBJETIVO: Verificar a associação entre posição prona, aumento da diurese e diminuição do balanço hídrico em pacientes pediátricos criticamente enfermos e submetidos à ventilação mecânica (VM) por causa pulmonar, além de descrever eventuais intercorrências relacionadas à aplicação dessa posição.

MÉTODOs: Estudo observacional retrospectivo. Pacientes submetidos à VM por causa pulmonar, com idade entre 1 mês e 12 anos no período entre janeiro de 2013 e dezembro de 2015, foram selecionados e divididos entre os que receberam posição prona (GP) e os que não receberam (GC) durante a internação na Unidade de Terapia Intensiva Pediátrica (Utip). Os dados foram analisados longitudinalmente de D1 a D4.

RESULTADOS: Foram analisados77 pacientes (GP=37 e GC=40). Em termos de características gerais, os grupos foram semelhantes entre si. Na comparação entre os grupos, não houve aumento da diurese ou diminuição do balanço hídrico cumulativo no grupo prona. Na análise longitudinal de D1 a D4, evidenciou-se que o GP apresentou maior diurese $(p=0,034)$ e menor balanço hídrico cumulativo ( $p=$ $0,001)$ no D2. Com relação ao uso de diuréticos, houve maior uso de furosemida $(P<0,001)$ e de espironolactona $(P=0,04)$ no $G P$. Não houve aumento de eventos adversos durante a utilização da posição prona. 
CONCLUSÃo: A posição prona não demonstrou associação com aumento da diurese ou diminuição de balanço hídrico cumulativo em pacientes críticos pediátricos submetidos à VM por causa pulmonar.

PALAVRAS-CHAVE: Decúbito ventral. Diurese. Balanço hídrico. Respiração com pressão positiva. Unidades de Terapia Intensiva PediátriCa.

\section{REFERENCES}

1. Lanetzki CS, Oliveira CA, Bass LM, Abramovici S, Troster El. The epidemiological profile of Pediatric Intensive Care Center at Hospital Israelita Albert Einstein. Einstein (Sao Paulo). 2012;10(1):16-21.

2. Einloft PR, Garcia PC, Piva JP, Bruno F, Kipper DJ, Fiori RM. A sixteen-year epidemiological profile of a pediatric intensive care unit, Brazil. Rev Saúde Pública. 2002;36(6):728-33

3. Kuiper JW, Groeneveld AB, Slutsky AS, Plötz FB. Mechanical ventilation and acute renal failure. Crit Care Med. 2005;33(6):1408-15.

4. Lubrano R, Cecchetti C, Elli M, Tomasello C, Guido G, Di Nardo M, et al. Prognostic value of extravascular lung water index in critically ill children with acute respiratory failure. Intensive Care Med. 2011;37(1):124-31.

5. Flori HR, Church G, Liu KD, Gildengorin G, Matthay MA. Positive fluid balance is associated with higher mortality and prolonged mechanica ventilation in pediatric patients with acute lung injury. Crit Care Res Pract. 2011;2011:854142.

6. Arikan AA, Zappitelli M, Goldstein SL, Naipaul A, Jefferson LS, Loftis LL. Fluid overload is associated with impaired oxygenation and morbidity in critically ill children. Pediatr Crit Care Med. 2012;13(3):253-8.

7. National Heart, Lung, and Blood Institute Acute Respiratory Distress Syndrome (ARDS) Clinical Trials Network, Wiedemann HP, Wheeler AP, Bernard GR, Thompson BT, Hayden D, deBoisblanc B, et al. Comparison of two fluid-management strategies in acute lung injury. N Engl | Med. 2006;354(24):2564-75

8. Kornecki A, Frndova H, Coates AL, Shemie SD. A randomized trial of prolonged prone positioning in children with acute respiratory failure. Chest. 2001;119(1):211-8.

9. Lopes CLS, Piva JP. Fluid overload in children undergoing mechanical ventilation. Rev Bras Ter Intensiva. 2017;29(3):346-53.
10. Slater A, Shann F, Pearson G; Paediatric Index of Mortality (PIM) Study Group. PIM2: a revised version of the Paediatric Index of Mortality. Intensive Care Med. 2003;29(2):278-85.

11. Brierley J, Carcillo JA, Choong K, Cornell T, Decaen A, Deymann A, et al. Clinical practice parameters for hemodynamic support of pediatric and neonatal septic shock: 2007 update from the American College of Critical Care Medicine. Crit Care Med. 2009;37(2):666-88

12. Curley MA, Thompson JE, Arnold JH. The effects of early and repeated prone positioning in pediatric patients with acute lung injury. Chest. 2000;118(1):156-63.

13. Mure M, Martling CR, Lindahl SG. Dramatic effect on oxygenation in patients with severe acute lung insufficiency treated in the prone position. Crit Care Med. 1997;25(9):1539-44.

14. Guérin C, Reignier J, Richard JC, Beuret $P$, Gacouin A, Boulain T, et al. Prone positioning in severe acute respiratory distress syndrome. N Engl Med. 2013;368(23):2159-68.

15. Gattinoni L, Carlesso E, Taccone P, Polli F, Guérin C, Mancebo I. Prone positioning improves survival in severe ARDS: a pathophysiologic review and individual patient meta-analysis. Minerva Anestesiol. 2010;76(6):448-54.

16. Sud S, Friedrich JO, Adhikari NK, Taccone P, Mancebo J, Polli F, et al. Effect of prone positioning during mechanical ventilation on mortality among patients with acute respiratory distress syndrome: a systematic review and meta-analysis. CMAJ. 2014;186(10):E381-90.

17. Donoso FA, Arriagada SD, Díaz RF, Cruces RP. Ventilation strategies in the child with severe hypoxemic respiratory failure. Gac Med Mex. 2015;151(1):75-84.

18. Fineman LD, LaBrecque MA, Shih MC, Curley MA. Prone positioning can be safely performed in critically ill infants and children. Pediatr Crit Care Med. 2006;7(5):413-22. 